\title{
MEDIDAS PREVENTIVAS E PROTETIVAS RELACIONADAS À COVID-19 EM UMA ASSOCIAÇÃO DE RECICLAGEM ${ }^{1}$
}

\section{Aline Costa Lopes²; Larissa Nunes3; Dirce Stein Backes4; Jerônimo Costa Branco $^{5}$}

RESUMO: Objetiva-se relatar a experiência realizada em uma Associação de Materiais Recicláveis, que teve como propósito promover medidas preventivas e protetivas de combate ao corona vírus COVID-19. Trata-se de um relato de experiência, desenvolvido no decorrer da disciplina de Interação Cientifico-Social do Mestrado em Ciências de Saúde e da Vida da Universidade Franciscana (UFN), no primeiro semestre de 2020, em uma Associação de Materiais Recicláveis da região central do Rio Grande do Sul. A experiência realizada demonstrou que as medidas preventivas e protetivas de combate ao corona vírus COVID-19 vão além da reprodução de informações ou saberes teóricos. Para que haja a adesão dos envolvidos é fundamental que ocorra um compartilhamento de saberes e práticas e a produção de conhecimentos significativos, capazes de repercutir em mudança de atitudes e comportamentos.

Palavras-Chave: Mascara de Proteção; Recicladores; Reciclagem; Relato de Experiência.

Eixo Temático: Atenção Integral e Promoção à Saúde

\footnotetext{
1 Trabalho apresentado a disciplina de Interação Cientifico-Social do Curso de Mestrado Acadêmico em Ciências da Saúde e da Vida da Universidade Franciscana - UFN.

2 Autor/ Apresentador. Mestre do Programa de Pós Graduação, Pesquisa e Extensão Mestrado Acadêmico em Ciências da Saúde e da Vida da Universidade Franciscana - UFN enfermeiraalainecosta@hotmail.com

${ }^{3}$ Demais autores. Mestre do Programa de Pós Graduação, Pesquisa e Extensão Mestrado Acadêmico em Ciências da Saúde e da Vida da Universidade Franciscana - UFN. larinutri2010@gmail.com

${ }^{4}$ Orientador. Doutora, Docente do Programa de Pós Graduação, Pesquisa e Extensão Mestrado Acadêmico em Ciências da Saúde e da Vida da Universidade Franciscana - UFN. backesdirce@unifra.br

5 Orientador. Doutor, Docente do Programa de Pós Graduação, Pesquisa e Extensão do Mestrado Acadêmico em Ciências da Saúde e da Vida da Universidade Franciscana - UFN. jeronimobranco@hotmail.com
} 


\section{INTRODUÇÃO}

A reciclagem consiste em minimizar os impactos negativos causados ao meio ambiente, pela ação do homem. Pela reciclagem é possível reaproveitar a matériaprima que já foi utilizada, a fim de contribuir para a redução da poluição (LOPES; NUNES, 2010).

Segundo Mol e Caldas (2020), é preciso que se discutam protocolos para o gerenciamento do lixo doméstico em tempos de pandemia, já que existem pacientes acometimentos pela COVID-19 em tratamento domiciliar, os quais geram resíduos infectados. Estes, por sua vez, são descartados como lixo doméstico e sem qualquer identificação, o que pode se representar em risco para os selecionadores de materiais recicláveis, para os seus familiares e para o meio ambiente.

Doremalen e colaboradores (2020) elucidam que a COVID-19 pode ser detectada em diferentes condições, conforme apresentado: até três horas após a aerossolização; até quatro horas em cobre; até 24 horas em papelão; e até dois a três dias em plástico e aço inoxidável. Essa viabilidade relativamente longa dos materiais estudados sugere risco potencial para a presença do vírus nos resíduos. Contudo, o vírus da COVID-19 pode ser facilmente inativado por agentes biocidas como: água sanitária, álcool $70 \%$ tanto na forma em gel como a em liquido, de tal modo enfatizando a importância dos procedimentos de higiene que são vistos como a chave para controlar a disseminação viral.

Conforme as orientações do Ministério da Saúde, além da lavagem de mãos com água, sabão, e álcool gel 70\%, a prevenção da COVID-19 pode se dar pela utilização de máscaras caseiras, as quais reduzem a sua incidência de forma significativa. A máscara deve ser confeccionada de forma correta, devendo cobrir totalmente a boca e nariz, sem deixar espaços nas laterais.

A Agência Nacional de Vigilância Sanitária - ANVISA (2020), ressalta que as máscaras são de uso individual, além disso precisa ser higienizada as mãos corretamente antes de sua colocação e após cada retirada. Vale ainda ressaltar que a máscara não pode ser manipulada durante o uso. No entanto, é necessário ter cuidado com o tempo da utilização de cada máscara, lavagem das mãos com maior 
frequência, evitando contato físico, aglomerações e locais públicos lotados, afim de garantir a proteção e impedir a disseminação dos agentes causadores da doença ou pelo próprio doente.

Com base no exposto, objetiva-se relatar a experiência realizada na Associação de Recicladoras de Santa-Maria, que teve o propósito de promover medidas preventivas e protetivas de combate ao corona vírus COVID-19.

\section{METODOLOGIA}

Trata-se de um relato de experiência vinculado à disciplina de Interação Cientifico-Social do Mestrado em Ciências de Saúde e da Vida da Universidade Franciscana (UFN), a qual foi desenvolvida no primeiro semestre de 2020. Realizouse, para tanto, intervenções em uma Associação de Materiais Recicláveis localizada na região central do Rio Grande do Sul, com base no detalhamento a seguir:

Primeiro Momento: Foi realizada uma homenagem para as selecionadoras de materiais recicláveis alusiva ao dia das mães. Neste dia as recicladoras foram agraciadas com um almoço especial e uma mensagem divulgada em um caro de som. Logo após a homenagem foram distribuídos kits com máscara de proteção, juntamente com uma toalha de rosto.

Segundo Momento: Foram realizadas discussões teórico-práticas preventivas e protetivas relacionadas a Lavagem frequente e correta das mãos, uso correto e higienização da máscara facial, importância do isolamento e minimização de aglomerações, dentre outros questionamentos.

Realizou-se, com base nestes questionamentos, demonstrações práticas de como fazer uma máscara de proteção com apenas uma camiseta e tesoura. Esta ação teve como objetivo incentivar o uso correto da máscara facial, bem como compartilhar com os amigos e familiares a forma simples, segura e barata de confeccionar a sua própria máscara.

Durante a confecção da máscara de proteção, algumas selecionadoras levantaram questões sobre o descarte correto da máscara, pela comunidade em geral. As mesmas relataram que, frequentemente, encontravam o descarte de máscaras junto com os demais resíduos domésticos. Este fato as angustiava pelo risco de 
contrair o vírus COVID-19, já que muitas pessoas se encontravam em quarentena nos domicílios.

Terceiro Momento: Diante do problema levantado pelas recicladoras e como alternativa de solução à problemática mencionada, foi realizado e produzido um folder, na forma ilustrativa, no sentido de possibilitar informações de como fazer o descarte correto da máscara facial doméstica. Este material foi divulgado em redes sociais, para conscientizar a população, em geral, quanto à necessidade das medidas preventivas e protetivas coletivas.

Quarto Momento: Realizou-se um novo encontro com as recicladoras, em seu ambiente de trabalho, isto é, na Associação de Materiais Recicláveis, no intuito de socializar o folder informativo e avaliar a efetividade das intervenções realizadas. Segue, a seguir, o folder informativo.

Figura 1: Folder informativo

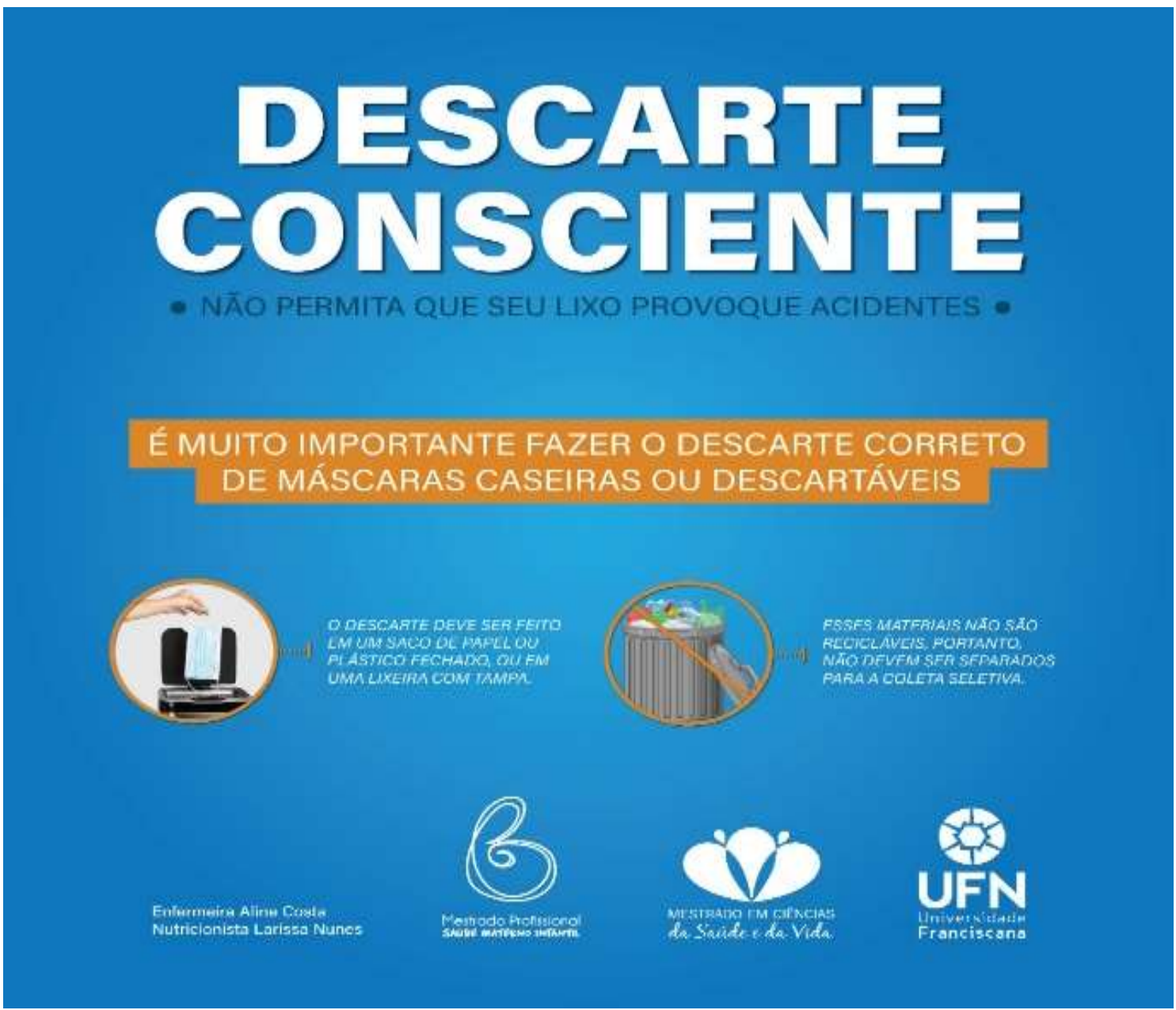




\section{RESULTADOS E DISCUSSÃO}

A educação em saúde vai muito além de mecanismos teóricos de intervenção. É preciso que se considere, nesse processo, as características de cada espaço, ambiente e características dos atores envolvidos. Foi com base nessa compreensão, que se desenvolveu atividades de interlocução na prática dos envolvidos, isto é, na realidade de trabalhadores de uma Associação de Materiais Reciclagem. Buscou-se, a partir de visitas in loco, conhecer e compreender a realidade e o modo operandis dos trabalhadores, que operam em condições de vulnerabilidade de toda ordem.

Evidenciou-se, desde o primeiro e o segundo momento, a necessidade do uso correto das máscaras pelas trabalhadoras, bem como o descarte correto destas pela população, em geral, no sentido de minimizar os riscos de contágio. Quando questionadas, as trabalhadoras referiram o descarte incorreto das máscaras domiciliares, o qual thes causava preocupação e insegurança, pela exposição aos riscos. Indicaram, porém, que a causa do problema estava relacionado à falta de conscientização da população em saber separar os resíduos sólidos a serem reciclados e a maneira correta de descartar as máscaras (DALL'AGNOL; FERNANDES, 2007).

Sues e Colaboradores (2011) observam, que o uso de máscaras caseiras são indicações bem oportunas como medida social de baixo custo para a população em geral. Taminato e Colaboradores (2020) pontuam que o uso de máscaras contribuem na proteção de indivíduos saudáveis, mas também na redução dos sintomas de pessoas sintomáticas, auxiliam na prevenção da transmissão, na diminuição da velocidade de espalhamento da doença, e consequentemente contribuem para achatar a curva epidêmica.

Além da preocupação com a Pandemia da Covid-19, a qual requer medidas rigorosas de proteção, os trabalhadores mencionaram que o descarte de máscaras não deve fazer parte da coleta seletiva com a intenção de conscientizar e proteger a saúde do dos trabalhadores. Através da separação dos resíduos nas residências brasileiras de forma correta, a reciclagem torna-se mais efetiva, fazendo com que haja 
uma diminuição nas incidências de doenças, acometendo a população que trabalha com a reciclagem (CARDOSO; CARDOS, 2016).

Mediante à problemática encontrada em relação ao descarte incorreto das máscaras, propôs-se um folder informativo e ilustrativo para orientar a população sobre o modo adequado do descarte correto das máscaras para divulgação nas redes sociais. Com intuito de divulgação e conforme a forma elucidada, houve uma grande repercussão após a publicação nas redes sociais, com retorno de forma positiva através de compartilhamentos, alcançando atividade proposta.

Mesquita e Colaboradores (2017) consideram, que as redes sociais são facilitadoras para o compartilhamento de informações e na divulgação de conteúdo informativo, em virtude disso tem sido utilizada por grande parte dos profissionais da saúde, assim facilitando o compartilhamento de informações para a população. Dessa forma, as pesquisadoras retornaram a Associação de Materiais Recicláveis e apresentaram o folder explicativo que está sendo divulgado nas redes sociais, mediante ao exposto as trabalhadoras relataram que houve uma melhora significante na conscientização do descarte correto de máscaras pela população.

Através do relato das trabalhadoras, surgiu não só questionamentos sobre a prevenção da Covid-19 mais também questões relacionadas a saúde das trabalhadoras e a importância de terem um acompanhamento psicológico no eu local de trabalho. Para Landim e Colaboradores (2017) o trabalho é um suporte central para manutenção da vida e, para a significação do eu no coletivo, também a maneira como os indivíduos vivem ou trabalham, está intimamente relacionada ao valor moral que é atribuído ao trabalho.

Por isso, é de grande valia que esta população tenha um acompanhamento psicológico, pois o adoecimento à partir do trabalho, assim como a capacidade de superação dos limites da doença, são dependentes de uma relação edificada socialmente entre o sujeito e o trabalho, de uma maneira muito particular e individualizada (LANDIM et al., 2017)

Pois a saúde mental é um estado completo de saúde, em termos de bem-estar físico, mental e social (OMS, 2016). Desta maneira, as trabalhadoras tiveram uma ideia de desenvolver o "Quadro dos Sentimentos", onde todas poderiam escrever as 
suas inquietações, angústias, alegrias e palavras de incentivos, além disso foi salientado a continuidade da divulgação do folder explicativos por meio das redes sociais.

\section{CONCLUSÃO}

A experiência realizada demonstrou, que as medidas preventivas e protetivas de combate ao corona vírus COVID-19 vão além de informações e a reprodução de saberes teóricos. Para que haja a adesão dos envolvidos é fundamental que ocorra um compartilhamento de saberes e práticas e a produção de conhecimentos significativos, capazes de repercutir em mudança de atitudes e comportamentos.

As fontes de divulgação e informação através das redes sociais são necessárias para alcançar milhares de pessoas, buscando a conscientização e orientando a população, através de compartilhamentos e visualizações alcançando não somente pessoas do seu bairro ou município e sim do mundo inteiro.

Por fim, concluímos através da experiência realizada, nossos objetivos propostos foram alcançados, tanto como no uso correto de mascaras, mas também na prevenção e conscientização da população do descarte correto, como também saímos sensibilizadas pelo trabalho realizado naquele local, e ao mesmo tempo é possível constatar a preocupação com o meio ambiente, saúde da população e com saúde dos trabalhadores.

É preciso dar continuidade ao trabalho realizado para conscientização das pessoas alertando a sociedade dos riscos contaminação e exposição do descarte incorreto de lixos e máscaras e o quão prejudicial pode ser para saúde dos trabalhadores enaltecendo o trabalho realizado pelas recicladoras.

\section{REFERÊNCIAS}

Agência Nacional de Vigilância Sanitária - ANVISA. Disponível em <http://portal.anvisa.gov.br/documents/219201/4340788/NT+M\%C3\%A1scaras.p df/bf430184-8550-42cb-a975-1d5e1c5a10f7> Acesso em 27 de Maio de 2020. 
CARDOSO, Fernanda de Cássia Israel; CARDOSO, Jean Carlos. O problema do lixo e algumas perspectivas para redução de impactos. Ciência e Cultura, v. 68, n. 4, p. 25-29, 2016.

DALL'AGNOL, Clarice Maria; FERNANDES, Fernanda dos Santos. Health and selfcare among garbage collectors: work experiences in a recyclable garbage cooperative. Revista Latino-Americana de Enfermagem, v. 15, n. spe, p. 729-735, 2007.

DOREMALEN, N, BUSHMAKER, T, MORRIS, DH, et al. (2020). Aerosol and surface stability of HCoV-19 (SARS-CoV-6 2) compared to SARS-CoV-1. 2020.03.09.20033217

LANDIM, José Marcondes Macêdo et al. Saúde Mental do Trabalhador no Brasil: Questões emergentes. ID on line REVISTA DE PSICOLOGIA, v. 10, n. 33, p. 186$197,2017$.

LOPES, Flavio Marques; MELO, Gomes De. Para Incentivo À Educação Ambiental E Um Colégio Estadual De Anápolis-Go.v. 13, p. 87-103, 2010.

MESQUITA, Ana Cláudia et al. Social networks in nursing work processes: an integrative literature review. Revista da Escola de Enfermagem da USP, v. 51, p. 1$12,2017$.

MINISTÉRIO DA SAÚDE. Disponível em https://coronavirus.saude.gov.br/sobrea-doencao-que-e-covid Acesso em 27 de Maio de 2020.

MOL, Marcos Paulo Gomes; CALDAS, Sérgio. Can the human coronavirus epidemic also spread through solid waste? Waste Management and Research, 2020. 


\section{QUFN}

Organização Mundial da Saúde. Objetivo de fortalecer e promover a saúde mental da população.Disponível

em

https://www.paho.org/bra/index.php?option=com_content\&view=article\&id=5263:opa s-oms-apoia-governos-no-objetivo-de-fortalecer-e-promover-a-saude-mental-dapopulacao\&Itemid=839> Acesso em 10 de junho .

Suess T, Remschmidt C, Schink SB, Schweiger B, Nitsche A, Schroeder K, et al. The role of facemasks and hand hygiene in the prevention of influenza transmission in households: results from a cluster randomised trial. Berlin, Germany, 20092011. BMC Infect Dis. $2012 ; 12(1): 26$.

TAMINATO, Monica et al. Máscaras de tecido na contenção de gotículas. p. 1-11, 2020. 